\title{
Avaliação da Silagem de Diferentes Híbridos de Milho (Zea mays, L.) por meio do Desempenho de Bezerros Confinados em Fase de Crescimento ${ }^{1}$
}

\author{
Joilmaro Rodrigo Pereira Rosa ${ }^{1}$, João Restle ${ }^{2}$, José Henrique Souza da Silva ${ }^{3}$, Leonir Luiz \\ Pascoal $^{4}$, Paulo Santana Pacheco ${ }^{5}$, Cristian Faturi ${ }^{6}$, Angélica Pereira dos Santos ${ }^{7}$
}

RESUMO - Objetivou-se avaliar, por meio do desempenho animal, silagens de três híbridos de milho (Zea mays, L.): Agroceres AG-5011, Braskalb XL-344 e Cargill C-806. Foram utilizados 27 machos, não-castrados, mestiços Nelore x Charolês, com idade média de 10 meses e peso médio inicial de $252 \mathrm{~kg}$, confinados durante 84 dias, subdivididos em quatro períodos de 21 dias. As silagens dos híbridos testados corresponderam a 70\% da matéria seca ofertada. Não houve interação do híbrido de milho testado com o período de avaliação em confinamento, para os parâmetros estudados. A dieta que incluiu a silagem do híbrido AG-5011 resultou em maior consumo voluntário médio diário de matéria seca, expresso por 100 kg de peso vivo e tamanho metabólico, e maior consumo médio diário de fibra em detergente ácido, expresso nas diferentes formas, em relação aos híbridos XL-344 e C-806, que, por sua vez, foram semelhantes entre si. As dietas que incluíram silagens dos híbridos AG-5011, XL-344 e C-806 apresentaram semelhanças quanto ao consumo voluntário de matéria seca, expresso em kg/animal/dia (6,73; 6,05; e 6,19), consumo médio diário de FDN, em kg/dia (3,054; 2,837; e 2,836), e energia digestível, expressa nas diferentes formas, ganho de peso médio diário, em kg/dia (1,283; 1,219; e 1,249), ganho em estado corporal, conversão alimentar (5,26; 4,98; e 4,97) e eficiência energética (14,02; 13,68; e 13,21). Os três híbridos são indicados como materiais genéticos de muito boa qualidade para produção de silagem, promovendo ganhos de peso diário superior a 1,2 kg/animal/dia, quando utilizados em dietas com relação volumoso:concentrado de 70:30.

Palavras-chave: bovino, consumo alimentar, conversão alimentar, eficiência energética, estado corporal, ganho de peso

\section{Evaluation of Silages of Different Corn Hybrids (Zea mays, L.) by Feedlot Performance of Calves, During the Growing Phase}

\begin{abstract}
The objective of the experiment was to evaluate, through feedlot performance of calves, three corn hybrids (Zea mays, L.): Agroceres AG-5011, Braskalb XL-344 and Cargill C-806. For the evaluation, 27 Nellore x Charolais non-castrated crossbred males with average age of 10 months and average initial weight of $252 \mathrm{~kg}$, were used. The animals were fed during 84 days, divided in four periods of 21 days. The hybrids silages tested represented $70 \%$ of the dry matter offered. No significant interaction of corn hybrids with evaluation period was observed for the different parameters. The diet that included the AG-5011, resulted in higher voluntary dry matter intake expressed per $100 \mathrm{~kg}$ of live weight and metabolic size, and higher average daily intake of ADF expressed in the different forms, in relation to XL-344 and C-806, which were similar to each other. The diets that included the AG-5011, XL-344 and C-806 silages showed similar dry matter intakes expressed as kg/animal/day (6.73; 6.05; and 6.19), NDF expressed as kg/animal/day (3.054; 2.837; and 2.836) and digestible energy expressed in the different forms, average daily weight gain (1.283; 1.219; and 1.249 kg), gain in body condition, feed conversion (5.26; 4.98; and 4.97) and energy efficiency (14.02; 13.68 ; and 13.21). The three hybrids are indicated as very good genetic materials for silage production, resulting in weight gain above 1.2 $\mathrm{kg} / \mathrm{animal} /$ day when fed diets with roughage:concentrate ratio of 70:30.
\end{abstract}

Key Words: body condition, cattle, daily weight gain, dry matter intake, energy efficiency, feed conversion

\footnotetext{
1 Parte da Dissertação apresentada à UFSM para obtenção do título de Mestre do primeiro autor.

2 Engenheiro-Agrônomo, MSc. Aluno do Programa de Pós-Graduação da UFRGS, Porto Alegre. E-mail: joilmaro@terra.com.br.

3 Engenheiro-Agrônomo, PhD, Pesquisador Visitante/CNPq - Departamento de Produção Animal - UFG. E.mail: jorestle@terra.com.br

4 Engenheiro-Agrônomo, PhD., Professor Titular do Departamento de Zootecnia da UFSM, Santa Maria-RS. E-mail: jhss@ccr.ufsm.br

5 Zootecnista, MSc. Professor do Departamento de Zootecnia da UFSM, Santa Maria-RS. E-mail: pascoall@terra.com.br

6 Zootecnista, MSc. Aluno de Doutorado do Programa de Pós-Graduação em Ciência Animal da UFG - Goiânia, GO.

7 Zootecnista, MSc. Aluno do Programa de Pós-Graduação da UNESP, Jaboticabal-SP.

8 Zootecnista, MSc. Aluna do Programa de Pós-Graduação da UFSM, Santa Maria-RS.
} 


\section{Introdução}

A grande dependência das pastagens e das condições climáticas são as maiores causas da baixa produtividade e da qualidade insatisfatória da produção de bovinos no Brasil. Dessa forma, a intensificação da produção bovina de corte apresenta a necessidade da utilização estratégica de forragens conservadas, principalmente na forma de silagem, em seu sistema produtivo, em complementação ao manejo de pastagens e em combinação com o uso racional de grãos, resíduos da lavoura ou subprodutos da agroindústria. O uso de silagem, segundo Mülbach (1999), é uma boa recomendação para compensar esta flutuação estacional no crescimento de pastos e uma maneira de tornar a produção pecuária menos dependente das condições climáticas.

Pimentel et al. (1998) relatam que, para produção de silagem, há necessidade de uma espécie forrageira com elevada produção de massa por unidade de área e que seja um alimento de alta qualidade para os animais. McDonald (1991) considera a planta de milho ideal para a ensilagem, uma vez que produz quantidade relativamente alta de matéria seca e pequena capacidade tampão e contém níveis adequados de carboidratos solúveis, de fermentação satisfatória para a população de bactérias produtoras de lactato.

Segundo Restle et al. (1999), a silagem de milho é um alimento volumoso de alto valor nutricional, principalmente por seu valor energético, sendo recomendada na alimentação de bovinos que adotam o sistema de produção intensiva.

Nesse contexto, a disponibilidade de alimento, na forma de silagem, adquire importância estratégica, uma vez que possibilita a comercialização de animais nos períodos economicamente mais favoráveis. O conhecimento do valor nutritivo da forragem ensilada, quando armazenada e removida adequadamente, permite o planejamento da taxa de ganho de peso dos animais, pois se parte de um material homogêneo, de composição química mensurável, possibilitando a confecção de dietas equilibradas nutricionalmente.

O cultivo de milho para a ensilagem oferece a oportunidade de se produzir um alimento volumoso de boa digestibilidade e alto potencial de consumo, razão pela qual é o preferido dos produtores. Todavia, a falta de informações sobre o potencial genético do grande número de híbridos existentes no mercado impossibilita o técnico e produtor de adquirirem conhecimentos necessários para a escolha do melhor material para produção de silagem.

Entre as inúmeras pesquisas encontradas na literatura, com relação à caracterização agronômica produtiva e qualitativa de diferentes híbridos de milho, há um consenso, entre os autores, da necessidade do estudo das respostas dos diferentes materiais genéticos, referentes ao consumo de alimentos e desempenho animal.

Os híbridos de milho, Agroceres AG-5011, Braskalb XL-344 e Cargill C-806, encontram-se disponíveis no mercado, sendo considerados materiais “top” de linha das empresas de melhoramento genético, para produção de silagem de alta qualidade e valor nutritivo. No entanto, poucas são as informações existentes referentes à resposta animal frente à utilização da silagem destes híbridos, quando comparados sob mesma condição.

Desta maneira, objetivou-se, com o presente trabalho, avaliar as silagens dos híbridos de milho AG-5011, XL-344 e C-806, por meio do desempenho em confinamento de machos não-castrados em fase de crescimento.

\section{Material e Métodos}

O experimento foi desenvolvido no Setor de Bovinocultura de Corte do Departamento de Zootecnia da Universidade Federal de Santa Maria, localizada fisiograficamente na Depressão Central do Estado do Rio Grande do Sul, a uma altitude de 95 m (DNPEA, 1973). Conforme a classificação de Köppen, o clima da região é o Cfa (subtropical úmido), com precipitação média anual de $1.769 \mathrm{~mm}$, temperatura média anual de $19,2^{\circ} \mathrm{C}$, média mínima de $9,3^{\circ} \mathrm{C}$ em julho e média máxima de $24,7^{\circ} \mathrm{C}$ em janeiro, insolação de 2.212 horas anuais com umidade relativa do ar de $82 \%$ (Moreno, 1961).

Avaliaram-se três tratamentos, correspondentes às dietas alimentares de bezerros em confinamento, durante a fase de crescimento, que incluíram como volumoso a silagem dos seguintes híbridos de milho: Agroceres AG-5011; Braskalb XL-344; e Cargill C-806.

As silagens foram produzidas em uma área experimental de 12 ha, com características de manejo e fertilidade de solo adequadas ao cultivo de milho, sendo 4 ha de lavoura para cada híbrido. As lavouras foram implantadas no período de 14 a 15 de dezembro de 1999, em sistema de plantio direto, sob resteva de 
aveia (Avena strigosa) + azevém (Lolium multiflorum), com espaçamento entre linhas de $0,9 \mathrm{~m}$ e profundidade de semeadura de $3,5 \mathrm{~cm}$, com distribuição de 5,5 sementes por metro linear. A adubação de base foi constituída de $450 \mathrm{~kg} / \mathrm{ha}$ de adubo NPK, na formulação 10-18-20, e a adubação nitrogenada, em cobertura, efetuada 30 dias após o plantio, foi de $150 \mathrm{~kg} / \mathrm{ha}$ de uréia.

As lavouras foram colhidas quando a maior parte dos grãos se encontrava entre os estádios pastoso e farináceo. Foi utilizada uma ensiladeira regulada para tamanho médio de picado de 1,0 a $1,5 \mathrm{~cm}$ e altura de corte média de $20 \mathrm{~cm}$. O material colhido foi compactado com o auxílio de um trator, em silos de superfície tipo “torta”, vedados e protegidos com lona plástica de polietileno de três camadas.

O período de confinamento foi conduzido entre 10 de agosto e 12 de novembro de 2000, subdividido em um período inicial de adaptação de 10 dias e mais quatro períodos de 21 dias.

As dietas experimentais apresentaram, em média, 13,3\% de proteína bruta, constituída pelas silagens dos três híbridos avaliados (70\%) e concentrado (30\%), com base na matéria seca, objetivando ganho de peso médio diário de 1,2 kg, conforme as exigências dos animais em cada período, segundo as recomendações do NRC (1996) para a categoria animal utilizada. A composição dos concentrados encontra-se na Tabela 1.

A alimentação foi fornecida à vontade, duas vezes ao dia, a primeira refeição foi ofertada às $8 \mathrm{~h}$ e a segunda, às $15 \mathrm{~h}$, diariamente, sendo colocado, primeiramente, o volumoso no comedouro, e sobre este o concentrado, efetuando-se em seguida a mistura. Diariamente, foi calculado o ajuste do fornecimento da quantidade de alimento na matéria verde, considerando-se sobra de $10 \%$ do material oferecido. O consumo voluntário dos alimentos foi registrado diariamente por meio da pesagem da quantidade oferecida e das sobras do dia anterior.

Foram utilizados 27 bezerros, mestiços Charolês/ Nelore, não-castrados, em fase de crescimento, com idade média inicial de 10 meses e peso médio inicial de $252 \mathrm{~kg}$. Os animais foram divididos em nove lotes, com três animais cada, equilibrado por peso, grupo genético e escore corporal, e, então, distribuídos aleatoriamente em nove boxes, sobre os quais foram sorteados os tratamentos. Os boxes pavimentados possuíam área com $20 \mathrm{~m}^{2}$, apresentavam cochos de concreto cobertos (1,30 m linear/animal), para forne- cimento de alimentos, e bebedouros com água à vontade, regulada por bóia automática.

Os animais foram submetidos a um período de adaptação de 10 dias às instalações, ao sistema de manejo e às dietas experimentais. Nesse período, receberam vacina contra clostridioses e antihelmíntico avançado, de largo espectro, conforme a recomendação do fabricante.

Os animais foram pesados e o estado corporal, avaliado, após jejum de alimentos de 14 horas, a cada 21 dias, correspondente ao período de avaliação, durante quatro períodos.

Amostras representativas dos componentes da dieta alimentar (concentrados e volumosos) foram coletadas no início da adaptação e a cada período de avaliação do experimento, sendo os volumosos présecados em estufa de ar forçado, a $60^{\circ} \mathrm{C}$, por 72 horas, para determinação do teor de matéria seca, e posteriormente, processadas em moinho tipo Willey, com peneira de malha de um milímetro. Nas amostras de cada alimento, foram determinados o teor de matéria seca (MS) e proteína bruta (PB), conforme AOAC (1984), a digestibilidade in vitro da matéria orgânica (DIVMO), segundo Tilley \& Terry (1963), e o teor de matéria orgânica (MO). O teor de fibra em detergente neutro (FDN) foi determinado conforme

Tabela 1 - Composição do concentrado das dietas, com base na matéria seca total, de acordo com o período experimental

Table 1 - Concentrate composition of the diets, total dry matter basis, according to the experimental period

\begin{tabular}{lcccc}
\hline \multirow{2}{*}{$\begin{array}{l}\text { Ingredientes } \\
\text { Ingredients }\end{array}$} & \multicolumn{4}{c}{$\begin{array}{c}\text { Períodos } \\
\text { Periods }\end{array}$} \\
\cline { 2 - 5 } $\begin{array}{l}\text { Aveia } \\
\text { Oat }\end{array}$ & 1 & 2 & 3 & 4 \\
$\begin{array}{l}\text { Farelo de soja } \\
\text { Soybean meal }\end{array}$ & 0,0 & 41,4 & 54,8 & 61,9 \\
$\begin{array}{l}\text { Uréia } \\
\text { Urea }\end{array}$ & 0,4 & 0,0 & 0,0 & 0,0 \\
$\begin{array}{l}\text { Calcário calcítico } \\
\text { Limestone }\end{array}$ & 2,5 & 2,8 & 1,9 & 2,3 \\
$\begin{array}{l}\text { Fosfato bicálcico } \\
\text { Dicalcium phosphate }\end{array}$ & 2,1 & 2,4 & 3,3 & 2,0 \\
$\begin{array}{l}\text { Cloreto de sódio } \\
\text { Salt }\end{array}$ & 0,5 & 0,4 & 0,4 & 0,4 \\
$\begin{array}{l}\text { Monensina sódica } \\
\text { Monensin }\end{array}$ & 0,002 & 0,002 & 0,002 & 0,002 \\
Total & 100,0 & 100,0 & 100,0 & 100,0 \\
\hline
\end{tabular}


Goering \& Van Soest (1970) e os de fibra em detergente ácido (FDA) e dos constituintes da fração fibrosa, hemicelulose (HEM), celulose (CEL) e lignina (LIG), segundo AOAC (1995).

Uma fração de cada amostra de silagem foi congelada na forma in natura e, posteriormente, triturada e utilizada para análise do $\mathrm{pH}$, por intermédio do potenciômetro digital (Digimed) e do nitrogênio amoniacal como porcentagem do nitrogênio total ( $\left.\mathrm{N}-\mathrm{NH}_{3} / \mathrm{NT}\right)$, conforme técnica descrita pelo AOAC (1995).

Os valores de nutrientes digestíveis totais (NDT) foram obtidos pela equação de regressão recomendada pela Latin American Tables of Feed Composition (1974), com base nas análises de PB, EE, FB e extrativos não nitrogenados (ENN). Para o cálculo de energia digestível (ED), utilizaram-se as equações descritas pelo ARC (1980), com base na digestibilidade in vitro da matéria orgânica (DIVMO) e matéria orgânica (MO), e, a partir desta, foi calculada a energia metabolizável (EM), multiplicando a ED pelo fator 0,82. Para o cálculo da energia líquida de mantença (ELm) e de ganho (ELg), foram adotadas as equações sugeridas pelo NRC (1996).

Quanto ao desempenho animal, foram considerados para avaliação os seguintes parâmetros: consumo médio diário de matéria seca (CMS), expresso em kg/ animal (CMSD), por $100 \mathrm{~kg}$ de peso vivo (CMSP) e por unidade de tamanho metabólico (CMSM), assim como o consumo médio diário de energia digestível (CED), expresso em Mcal/animal (CEDD), Mcal por $100 \mathrm{~kg}$ de peso vivo (CEDP) e por unidade de tamanho metabólico (CEDM), ganho de peso médio diário (GMD), ganho de escore corporal (GEC), segundo Restle (1972), conversão alimentar (CA) e eficiência energética (CE). Também foram avaliados os consumos médios diários de fibra em detergente neutro (CFDN) e fibra em detergente ácido (CFDA), em kg/animal (CFDND e CFDAD), por $100 \mathrm{~kg}$ de peso vivo (CFDNP e CFDAP) e por unidade de tamanho metabólico (CFDNM e CFDAM).

$\mathrm{Na}$ avaliação do desempenho animal, adotou-se delineamento experimental inteiramente casualizado, composto por três tratamentos (silagens de milho AG-5011; XL-344 e C-806), com três repetições, em que cada unidade experimental foi composta por um lote com três animais. Os dados coletados foram submetidos à análise de variância, aplicando-se os testes $\mathrm{F}$ e Tukey, quando o $\mathrm{F}$ foi significativo a $5 \%$ de significância, deacordo como seguintemodelo estatístico:

$$
\mathrm{Y}_{\mathrm{ijk}}=\mu+\tau_{\mathrm{i}}+\alpha_{\mathrm{j}}\left(\tau_{\mathrm{i}}\right)+\beta_{\mathrm{k}}+(\tau \beta)_{\mathrm{ik}}+\varepsilon_{\mathrm{ij}}
$$

em que: $Y_{\mathrm{ijk}}$ refere-se às variáveis dependentes; $\mu$, à média das observações; $\tau_{1}$, ao efeito do i-ésimo tratamento (híbrido de milho), sendo 1 (silagem AG5011), 2 (silagem XL-344) e 3 (silagem C-806); $\alpha_{j}\left(\tau_{i}\right)$, ao efeito da j-ésima repetição, representando 1 para o lote 1, 2 para o lote 2 e 3 para o lote 3 , dentro do tratamento (i) - (Erro a); $\beta_{\mathrm{k}}$, ao efeito do período de confinamento, de ordem $\mathrm{k}$, sendo 1 (primeiro período), 2 (segundo período), 3 (terceiro período) e 4 (quarto período); $(\tau \beta)_{\mathrm{ik}}$, à interação do tratamento (i) com o período $(\mathrm{k}) ; \varepsilon_{\mathrm{ij}}$, à variação aleatória residual - (Erro b).

A interação do tratamento com o período $\left(\tau^{*} \beta\right)$, inicialmente testada, foi retirada do modelo estatístico final, em razão de sua não-significância( $(\mathrm{P}=0,05)$. $\mathrm{O}$ efeito de período (dias) sobre as variáveis dependentes foi avaliado dentro dos tratamentos e, também, submetido à análise de regressão polinomial, por meio do procedimento "proc reg”. As análises estatísticas foram realizadas utilizando-se o pacote estatístico SAS (SAS, 1997).

\section{Resultados e Discussão}

Na Tabela 2, são apresentados os resultados da análise bromatológica dos alimentos utilizados na formulação das dietas experimentais.

Verifica-se que o conteúdo de MS da silagem do AG-5011 foi superior ao dos outros híbridos, que apresentaram teores similares entre si. O momento da colheita dos híbridos foi determinado quando a maior parte dos grãos se encontrava entre os estádios pastoso a farináceo. No entanto, a determinação do ponto de colheita baseou-se apenas na consistência do grão, sem levar em consideração as variações quanto aos demais componentes da planta, como a maturidade das folhas e o conteúdo de água no colmo. Além disso, no momento da colheita, as plantas apresentaram certa desuniformidade quanto ao estádio de desenvolvimento, pois a germinação não ocorreu de maneira uniforme, em função do déficit hídrico, que foi mais evidente no híbrido XL344.

A DIVMO, ED e o NDT foram similares entre os três híbridos (Tabela 2). Estes resultados indicam que o conteúdo energético não foi afetado pelo teor de umidade do material ensilado, uma vez que são materiais genéticos distintos e o efeito do teor de umidade - reflexo do estádio de desenvolvimento da planta deve ser avaliado dentro do mesmo híbrido.

R. Bras. Zootec., v.33, n.4, p.1016-1028, 2004 
À medida que avança o estádio de maturação da planta, ocorre maior concentração de amido no grão (Andriguetto et al., 1981), diminuindo o teor de umidade não somente no grão, como também na planta, em função do avanço do estádio de maturação. Sabe-se também, que, ao mesmo tempo, a digestibilidade dos componentes da planta, causada pela lignificação da parede celular (Nussio, 1999), é reduzida. Além disso, ocorrem alterações na concentração de carboidratos solúveis na planta (Mühlbach, 1999). A velocidade com que ocorrem estes processos deve ser diferente entre os híbridos. Embora estes aspectos não tenham sido avaliados no presente experimento, sabe-se que os mesmos afetam a digestibilidade e, por conseqüência, o valor energético da silagem.

O conteúdo de água da massa ensilada, por si só, sem considerar sua relação com os demais aspectos, tem influência na qualidade final e na manutenção da silagem, além de interferir na compactação do material ensilado (dentro de certos limites, o teor de umidade favorece a compactação), afetando a quantidade e a velocidade com que o oxigênio é expulso, influenciando, portanto, o processo de fermentação. Além disso, quando o teor de umidade é muito elevado, ocorre perda de água, que carreia nutrientes presentes no conteúdo celular (Van Soest, 1994). No entanto, nos três materiais ensilados, não foi observada perda de líquidos após ensilagem.

Na Tabela 3, são apresentados os resultados médios de consumo de matéria seca (CMS) e energia digestível (CED), expressos em suas diferentes formas, de acordo com o híbrido de milho testado. Não houve interação $(\mathrm{P}=0,05)$ do híbrido de milho testado com o período de avaliação em confinamento, para CMS e CED.

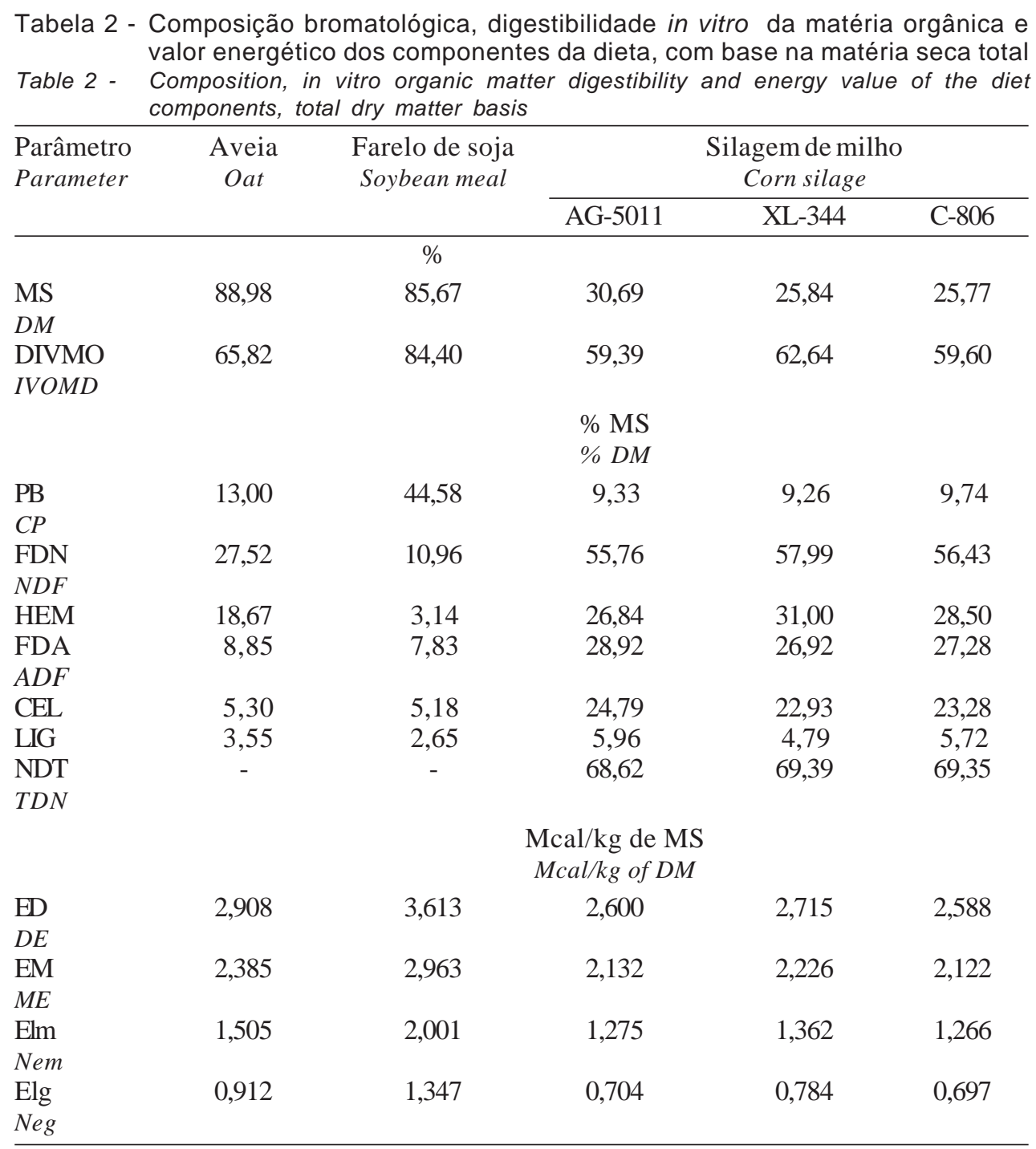

R. Bras. Zootec., v.33, n.4, p.1016-1028, 2004 
O consumo voluntário médio diário, por animal, foi similar $(\mathrm{P}=0,05)$ para as dietas que continham os diferentes híbridos. No entanto, quando o CMS foi expresso em kg/100 $\mathrm{kg}$ de peso vivo e $\mathrm{g} / \mathrm{kg}^{0,75}$, verificou-se que a dieta com o híbrido AG-5011 resultou em maior $(\mathrm{P}<0,05) \mathrm{CMSP}$ e CMSM frente à dieta que continha o XL-344. A dieta com a silagem do híbrido C-806 resultou em consumo intermediário, não diferindo $(\mathrm{P}=0,05)$ dos dois outros híbridos. Mertens (1992) cita que, para dietas que limitam o consumo pela distenção ruminal, o consumo voluntário é mais bem representado pelo consumo percentual, e, para dietas que limitam fisiologicamente o consumo, a melhor forma de expressão é em relação ao peso corporal metabólico. No presente experimento, verificou-se que ambas as formas de expressão do consumo voluntário mantiveram a mesma ordem de classificação das dietas.
Os maiores CMSP e CMSM, observados para a dieta do AG-5011, devem-se, em parte, ao maior teor de matéria seca desta silagem. Eifert (2000) justifica, entre outros fatores, que o consumo de alimentos possui estreita relação com o teor de matéria seca presente na dieta, uma vez que a quantidade de volumoso presente na dieta, associada a maiores conteúdos de água, determina o espaço ocupado no rúmen e pode limitar o consumo pelo efeito da distensão ruminal.

Verifica-se, na Tabela 2, que o teor de MS das silagens do XL-344 (25,84\%) e C-806 (25,77\%) foram similares e inferiores ao do AG-5011 (30,69\%). Já o CMSP e CMSM do AG-5011 (Tabela 3), embora numericamente superior aos outros dois, diferiu significativamente apenas da dieta que incluiu a silagem do XL-344. Isto concorda com Mertens (1992), indicando que o consumo voluntário de alimento é regu-

Tabela 3 - Consumo médio diário de matéria seca (CMS) e energia digestível (CED), expresso em kg/animal e Mcal/animal (CMSD e CEDD), por $100 \mathrm{~kg}$ de peso vivo (CMSP e CEDP), por unidade de peso metabólico (CMSM e CEDM), de acordo com o híbrido de milho

Table 3 - Average daily dry matter intake (DMI) and digestible energy intake (DEI), per animal (DMID and DEID), per $100 \mathrm{~kg}$ of live weight (DMIP and DEIP), per unit of metabolic weight (DMIM and DEIM), according to corn hybrid

\begin{tabular}{|c|c|c|c|}
\hline \multirow{3}{*}{$\begin{array}{l}\text { Híbrido de milho } \\
\text { Corn hybrid }\end{array}$} & \multicolumn{3}{|c|}{$\begin{array}{c}\text { Consumo diário de matéria seca (CMS) } \\
\text { Daily dry matter intake (DMI) }\end{array}$} \\
\hline & CMSD & CMSP & CMSM \\
\hline & $\begin{array}{c}D M I D \\
\mathrm{~kg} / \mathrm{animal}\end{array}$ & $\begin{array}{l}\text { DMIP } \\
\% \mathrm{PV}\end{array}$ & $\begin{array}{c}\text { DMIM } \\
\mathrm{g} / \mathrm{kg}^{0,75}\end{array}$ \\
\hline AG-5011 & 6,73 & $2,20 a$ & $91,95 a$ \\
\hline XL-344 & 6,05 & $2,00 \mathrm{~b}$ & $83,54 b$ \\
\hline C-806 & 6,19 & $2,02 \mathrm{ab}$ & $84,64 \mathrm{ab}$ \\
\hline Média & 6,32 & 2,08 & 86,71 \\
\hline \multicolumn{4}{|l|}{ Mean } \\
\hline $\mathrm{NS}^{1}$ & 0,0603 & 0,0494 & 0,0497 \\
\hline \multirow[t]{2}{*}{ CV $(\%)$} & 4,61 & 3,86 & 4,91 \\
\hline & \multicolumn{3}{|c|}{$\begin{array}{c}\text { Consumo diário de energia digestível (CED) } \\
\text { Daily digestible energy intake (DEI) }\end{array}$} \\
\hline Híbrido de milho & CEDD & CEDP & CEDM \\
\hline Corn hybrid & $\begin{array}{c}D E I D \\
\text { Mcal/animal }\end{array}$ & $\begin{array}{c}\text { DEIP } \\
\text { Mcal/100 kgPV }\end{array}$ & $\begin{array}{c}D E I M \\
\text { Mcal } / \mathrm{kg}^{0,75}\end{array}$ \\
\hline AG-5011 & 17,96 & 5,86 & 0,245 \\
\hline XL-344 & 16,60 & 5,50 & 0,229 \\
\hline C-806 & 16,45 & 5,38 & 0,225 \\
\hline Média & 17,00 & 5,58 & 0,233 \\
\hline Mean & & & \\
\hline $\mathrm{NS}^{1}$ & 0,1027 & 0,0757 & 0,0815 \\
\hline CV $(\%)$ & 4,58 & 3,83 & 3,99 \\
\hline
\end{tabular}

${ }^{1}$ NS - Nível de significância.

${ }^{1}$ NS - Significance level.

a,b Médias na mesma coluna, seguidas de letras diferentes, diferem $(P<0,05)$ pelo teste $F$. $a, b$, Means, within a column, followed by different letters, are different $(P<.05)$ by $F$ test.

R. Bras. Zootec., v.33, n.4, p.1016-1028, 2004 
lado por vários fatores ligados ao animal (peso vivo, nível de produção, estado fisiológico e outros), ao alimento (fibra, densidade energética, volume e outros) e às condições de alimentação (disponibilidade de alimento, freqüência de alimentação, tempo de acesso ao alimento, entre outros), além da interação destes fatores. Além disso, fatores ambientais aos quais o animal está exposto também podem afetar o consumo (NRC, 1996). No presente experimento, o único fator que variou na alimentação foi o tipo de silagem.

Fazendo uma avaliação da concentração energética das silagens, observa-se, na Tabela 2, que o AG-5011, o XL-344 e o C-806 apresentaram teores de $\operatorname{ED~(2,600;~2,715~e~2,588~Mcal/kg~de~MS)~e~de~}$ NDT $(68,62 ; 69,39$ e $69,35 \%)$ muito similares. Portanto, é pouco provável que as diferenças no CMSP e CMSM tenham sido causadas por fatores fisiológicos ligados à concentração energética das dietas, que apresentaram elevada proporção de volumoso.

Por outro lado, avaliando os teores dos componentes da parede celular das silagens, constata-se que o teor de FDN, embora sem diferença significativa, deve ter contribuído na quantidade de MS consumida (Tabela 2). Verificou-se que a ordem na concentração de FDN das silagens, 57,99\% (XL-344) $56,43 \%$ (C-806) e 55,76\% (AG-5011), foi inversa à ordem do CMSP, 2,0\% (XL-344) 2,02\% (C-806) e 2,2\% (AG-5011). Para os híbridos AG-5011 e XL-344, notou-se diferença, no CMSP, de 10\% a favor do AG-5011, enquanto, no XL-344, as concentrações de FDN e HEM foram numericamente 4 e $15 \%$ superiores, respectivamente. Segundo Waldo (1986), a FDN é o melhor e mais simples fator para predizer o consumo voluntário. Mertens (1992) também afirma que a FDN mede melhor a propriedade dos alimentos em ocupar espaço físico que os componentes fibra bruta e FDA.

Além do teor de MS e FDN, outro fator que afeta o consumo da silagem é o odor, que pode ser alterado pela fermentação do material ensilado. Quando ocorre fermentação indesejável, o odor característico da silagem pode ser alterado, influenciando negativamente sua aceitabilidade, causando rejeição do material ofertado (Brondani \& Alves Filho, 1998). Duas medidas relacionadas ao tipo de fermentação da silagem são o pH e o nitrogênio amoniacal, apresentados na Tabela 4.

Verifica-se que o pH das silagens dos três híbridos foram muito similares, estando abaixo do $\mathrm{pH} 4,2$, considerado, por vários autores (Mühlbach, 1999;
Van Soest, 1994; Fancelli \& Dourado-Neto, 2000), limite para uma silagem de boa qualidade. Mesmo sem conhecer a velocidade de redução do $\mathrm{pH}$, durante o processo de fermentação, estes materiais podem ser classificados, com base neste critério, de acordo com Borges et al. (1997), como silagens de muito boa qualidade. Elizalde (1995) ressalta que a resposta do aumento do consumo voluntário deve ser interpretada como um efeito de melhoria da qualidade de fermentação da massa ensilada.

Considerando o nitrogênio amoniacal das silagens, observa-se que, na silagem do XL-344, houve maior concentração de $\mathrm{N}-\mathrm{NH}_{3} / \mathrm{NT}$. Este resultado é indicativo de que ocorreu catabolismo de aminoácidos (McDonald et al., 1991). É possível que o teor de amônia tenha afetado o CMSP e CMSM da dieta que continha a silagem do XL-344. No entanto, o teor de $\mathrm{N}-\mathrm{NH}_{3} / \mathrm{NT}$ esteve abaixo dos $10 \%$, que, segundo Borges et al. (1997), a classifica como de muito boa qualidade. É provável que o menor consumo voluntário, verificado na dieta que incluiu a silagem do XL-344, tenha sido uma combinação dos teores de MS, FDN e $\mathrm{N}-\mathrm{NH}_{3} / \mathrm{NT}$.

Cabe ressaltar que, embora os teores de umidade da silagem do XL-344 e C-806 tenham sido muito similares, ocorreu diferença significativa no teor do $\mathrm{N}-\mathrm{NH}_{3} / \mathrm{NT}$. Esta constatação indica que, além do conteúdo de água, há outros fatores envolvidos no processo de produção de amônia.

O CMSP variou de 2,02 a 2,20\%, apresentando como média 2,08\%, valor inferior ao encontrado por Bail et al. (2000), utilizando animais das raças Charolês e Nelore e seus mestiços, alimentados com silagem de milho na relação 70:30, que observaram média de consumo de 2,23\%, e ao relatado por Pilar et al. (1994), com cruzados Blonde D’Aquitaine x Caracu, que encontraram 2,19\%, com relação volumoso:concentrado de 67,5:32,5.

Tabela 4 - Teores de pH e nitrogênio amoniacal no nitrogênio total $\left(\mathrm{N}-\mathrm{NH}_{3} / \mathrm{NT}\right)$ das silagens dos diferentes híbridos de milho

Table 4 - Levels of $\mathrm{pH}$ and ammonia nitrogen $\left(\mathrm{N}-\mathrm{NH}_{3}\right)$ of silages of different corn hybrids

\begin{tabular}{lccc}
\hline \multirow{2}{*}{$\begin{array}{l}\text { Parâmetro } \\
\text { Parameter }\end{array}$} & \multicolumn{3}{c}{$\begin{array}{c}\text { Silagem de milho } \\
\text { Corn silage }\end{array}$} \\
\cline { 2 - 4 } & AG-5011 & XL-344 & C-806 \\
\hline $\mathrm{pH}$ & 3,41 & 3,45 & 3,38 \\
$\mathrm{~N}^{-N_{3}} / \mathrm{NT}$ - \% & 5,43 & 8,03 & 5,22 \\
\hline
\end{tabular}


Em relação ao CED, expressos em suas diferentes formas, não houve diferença significativa $(\mathrm{P}=0,05)$ entre as dietas que incluíram as silagens dos diferentes híbridos, apesar do maior CMSP e CMSM da silagem do AG-5011 em relação ao XL-344, o que é explicado pela maior quantidade de energia digestível encontrada no XL-344 (2,715 Mcal/kg de MS) em relação ao AG-5011 (2,600 Mcal/kg de MS). As dietas que incluíram as silagens dos híbridos avaliados apresentaram valor médio para CEDD de 17,00 Mcal/dia. O CEDP, de 5,58 Mcal/100 kg PV, foi inferior aos consumos relatados por Costa (2001), de 6,52 Mcal/ $100 \mathrm{~kg}$ PV, Bail et al. (2000), de 6,92 Mcal/100 kg PV, Flores (1997), que avaliando animais Braford e $3 / 4$ Charolês $1 / 4$ Nelore, na terminação de superprecoces, encontrou valores entre 6,7 e 7,4 Mcal/100 kg PV, e Restle et al. (2000), que encontraram CEDP de 7,22 Mcal/100 kg PV, para novilhos em fase de crescimento que receberam uma dieta com silagem de milho, na proporção de $67,5 \%$, com base na matéria seca oferecida.

Na Tabela 5, são apresentados os resultados médios de consumo dos constituintes da parede celular, expressos nas diferentes formas, referentes ao período de confinamento dos animais, de acordo com o híbrido de milho testado. Não houve interação $(\mathrm{P}=0,05)$ do híbrido com o período de avaliação. Os consumos dos constituintes da parede celular da planta (FDN, FDA, hemicelulose e celulose) foram avaliados em função do CMS e de suas concentrações na matéria seca dos volumosos.

Verifica-se, na Tabela 5, que o CFDN expresso nas diferentes formas não diferiu $(\mathrm{P}=0,05)$ entre os híbridos de milho testados. Apesar de a silagem do AG-5011 apresentar maior $(\mathrm{P}<0,05)$ CMSP e CMSM que o XL-344, esta diferença foi compensada pelo

Tabela 5 - Consumo médio diário de fibra em detergente neutro (CFDN) e fibra em detergente ácido (CFDA), expresso em kg/dia (CFDND e CFDAD), por $100 \mathrm{~kg}$ de peso vivo (CFDNP e CFDAP) e por unidade de tamanho metabólico (CFDNM e CFDAM), de acordo com o híbrido de milho

Table 5 - Average daily neutral detergent fiber intake (NDFI) and daily acid detergent fiber intake (ADFI), per animal (NDFID and ADFID) per $100 \mathrm{~kg}$ of live weight (NDFIP) and $A D F I P)$, per unit of metabolic weight (NDFIM and ADFIM), according to corn hibrid

\begin{tabular}{|c|c|c|c|}
\hline \multirow{3}{*}{$\begin{array}{l}\text { Híbrido de milho } \\
\text { Corn hibrid }\end{array}$} & \multicolumn{3}{|c|}{$\begin{array}{c}\text { Consumo diário de fibra em detergente neutro (CFDN) } \\
\text { Daily neutral detergent fiber intake (NDFI) }\end{array}$} \\
\hline & CFDN & CFDNP & CFDNM \\
\hline & $\begin{array}{c}\text { NDFID } \\
\text { (kg/animal) }\end{array}$ & $\begin{array}{l}\text { NDFIP } \\
(\% \mathrm{PV})\end{array}$ & $\begin{array}{c}\text { NDFIM } \\
\left(\mathrm{g} / \mathrm{kg}^{0,75}\right)\end{array}$ \\
\hline AG-5011 & 3,054 & 1,00 & 41,70 \\
\hline XL-344 & 2,837 & 0,94 & 39,20 \\
\hline C-806 & 2,836 & 0,93 & 38,78 \\
\hline Média & 2,909 & 0,95 & 39,89 \\
\hline \multicolumn{4}{|l|}{ Mean } \\
\hline $\mathrm{NS}^{1}$ & 0,1461 & 0,1216 & 0,1268 \\
\hline \multirow[t]{2}{*}{$\mathrm{CV} \%$} & 4,55 & 3,82 & 3,97 \\
\hline & \multicolumn{3}{|c|}{$\begin{array}{c}\text { Consumo diário de fibra em detergente ácido (CFDA) } \\
\text { Daily acid detergent fiber intake (ADFI) }\end{array}$} \\
\hline Híbrido de milho & CFDAD & CFDAP & CFDAM \\
\hline Corn hibrid & $\begin{array}{c}A D F I D \\
\text { (kg/animal) }\end{array}$ & $\begin{array}{l}A D F I P \\
(\% \mathrm{PV})\end{array}$ & $\begin{array}{c}A D F I M \\
\left(\mathrm{~g} / \mathrm{kg}^{0,75}\right)\end{array}$ \\
\hline$\overline{\mathrm{AG}-5011}$ & $1,526 \mathrm{a}$ & $0,50 \mathrm{a}$ & 20,84 a \\
\hline XL-344 & $1,285 \mathrm{~b}$ & $0,43 \mathrm{~b}$ & $17,76 \mathrm{~b}$ \\
\hline C-806 & $1,332 \mathrm{~b}$ & $0,44 \mathrm{~b}$ & $18,21 \mathrm{~b}$ \\
\hline Média & 1,381 & 0,45 & 18,94 \\
\hline Mean & & & \\
\hline $\mathrm{NS}^{1}$ & 0,0088 & 0,0050 & 0,0057 \\
\hline $\mathrm{CV} \%$ & 4,72 & 3,92 & 4,09 \\
\hline
\end{tabular}

R. Bras. Zootec., v.33, n.4, p.1016-1028, 2004 
menor teor de FDN encontrado na silagem do AG-5011 (55,76\%) vs. XL-344 (57,99\%). Segundo Van Soest (1994), a FDN é a porção do componente fibra que melhor caracteriza o efeito de enchimento ruminal, uma vez que representa os constituintes da parede celular do alimento, tendo alta relação com o volume ocupado pela dieta. Os resultados médios encontrados do CFDNP (0,95\%) foram inferiores aos observados por Restle et al. (2004), que encontraram 1,32\%, avaliando as silagens dos híbridos de milho AG-5011 e AG-6018, por meio de novilhos Red Angus confinados em fase de crescimento.

O CFDA, expresso nas diferentes formas, foi influenciado pela fonte do volumoso $(\mathrm{P}<0,05)$, sendo que as dietas com silagem de milho AG-5011 apresentaram maior CFDAP $(0,50 \%)$ em relação aos híbridos XL-344 (0,43\%) e C-806 (0,44\%). Os maiores consumos foram determinados pelo maior teor de FDA encontrado na silagem do AG-5011 (28,92\%), em relação ao XL-344 (26,92\%) e C-806 (27,28\%), e também pelo maior CMSD dos animais que recebe- ram a silagem do AG-5011 (6,73kg), em relação ao XL-344 (6,05kg) e C-806 (6,19kg). A FDA representa a porção menos digestível da fibra, sendo um dos parâmetros medidos em laboratório relacionados com a digestibilidade dos alimentos. Os valores médios encontrados para CFDAP $(0,45 \%)$ foram inferiores aos observados por Restle et al. (2002), que encontraram $0,83 \%$.

Na Tabela 6, são apresentados os valores médios para as variáveis peso inicial (PI), peso final (PF), escore corporal inicial (ECI), escore corporal final (ECF), ganho de peso médio diário (GMD), ganho de estado corporal (GEC), conversão alimentar (CA) e eficiência energética (CE), conforme o híbrido de milho testado. Não houve interação $(\mathrm{P}=0,05)$ do híbrido de milho com o período de avaliação de confinamento, para estas variáveis. Observa-se, na Tabela 6, que não houve diferença $(\mathrm{P}=0,05)$ entre as silagens dos diferentes híbridos, para GMD, CA e CE. A semelhança no GMD é o reflexo do CED, expresso nas diferentes formas. Embora tenha ocorrido

Tabela 6 - Peso inicial (PI), peso final (PF), escore corporal inicial (ECI), escore corporal final (ECF), ganho de peso médio diário (GMD), ganho de estado corporal (GEC), conversão alimentar (CA) e eficiência energética (CE) de machos confinados, de acordo com o híbrido de milho

Table 6 - Initial weight (IW), final weight (FW), initial body condition (IBC), final body condition ( $F B C)$, average daily weight gain ( $A D G)$, body condition gain $(B C G)$, feed conversion (FC), and energy efficiency (EE) of confined males, according to corn hibrid

\begin{tabular}{|c|c|c|c|c|c|c|}
\hline \multirow[t]{2}{*}{$\begin{array}{l}\text { Parâmetros } \\
\text { Parameters }\end{array}$} & \multicolumn{3}{|c|}{$\begin{array}{l}\text { Híbridos de milho } \\
\text { Corn hybrids }\end{array}$} & \multirow[t]{2}{*}{$\begin{array}{l}\text { Média } \\
\text { Mean }\end{array}$} & \multirow[t]{2}{*}{$\mathrm{NS}^{1}$} & \multirow[t]{2}{*}{$\mathrm{CV}(\%)$} \\
\hline & AG-5011 & XL-344 & C-806 & & & \\
\hline $\begin{array}{l}\text { PI, kg } \\
I W\end{array}$ & 252,4 & 250,4 & 253,4 & 252,1 & 0,2998 & 0,86 \\
\hline $\begin{array}{l}\mathrm{PF}, \mathrm{kg} \\
F W\end{array}$ & 360,1 & 352,8 & 358,3 & 357,1 & 0,5106 & 2,13 \\
\hline $\begin{array}{l}\mathrm{ECI}^{2} \\
\mathrm{IBC}\end{array}$ & 2,91 & 3,07 & 2,95 & 2,98 & 0,0647 & 2,23 \\
\hline $\begin{array}{l}\mathrm{ECF}^{2} \\
\mathrm{FBC}\end{array}$ & 3,62 & 3,68 & 3,70 & 3,67 & 0,6754 & 3,27 \\
\hline $\begin{array}{l}\text { GMD, kg/dia } \\
A D G\end{array}$ & 1,283 & 1,219 & 1,249 & 1,250 & 0,7273 & 7,64 \\
\hline $\begin{array}{l}\text { GEC } \\
B C G\end{array}$ & 0,71 & 0,61 & 0,75 & 0,69 & 0,4816 & 19,28 \\
\hline $\begin{array}{l}\text { CA } \\
\text { FC }\end{array}$ & 5,26 & 4,98 & 4,97 & 5,07 & 0,5569 & 6,86 \\
\hline $\begin{array}{l}\mathrm{CE} \\
\mathrm{EE}\end{array}$ & 14,02 & 13,68 & 13,21 & 13,64 & 0,5979 & 6,88 \\
\hline
\end{tabular}

R. Bras. Zootec., v.33, n.4, p.1016-1028, 2004 
maiores CMSP e CMSM no híbrido AG-5011, não houve diferenças no CEDD, CEDP e CEDM - fator determinante do ganho de peso dos animais (NRC, 1996; Restle et al. 2000). Verificou-se, também, que os teores de umidade e amônia da silagem dos diferentes híbridos não afetaram o GMD, CA e CE.

A média obtida dos resultados do GMD (1,250kg/dia) evidencia a alta qualidade dos materiais genéticos avaliados para a produção de silagem, principalmente se for considerado a elevada participação da fração volumosa na dieta, correspondente a $70 \%$ do total da matéria seca ofertada. Os ganhos de peso foram similares aos encontrados por Costa (2001), que, utilizando relação volumoso:concentrado de 56,2:43,8, obteve ganho médio de 1,243 kg/dia, com animais Red Angus. Valores mais baixos para GMD são relatados por Bail et al. (2000), também utilizando silagem de milho como volumoso na relação 70:30, que observaram GMD de 1,080 kg, e por Pilar et al. (1994), que, trabalhando com relação volumoso:concentrado de 67,5:32,5, obtiveram GMD de 0,890 kg/dia. Com relação ao ganho de estado corporal (GEC), que mede a deposição de gordura subcutânea, não houve diferença significativa $(\mathrm{P}=0,05)$ entre os híbridos de milho testados, apresentando ganho médio de 0,69 pontos no estado corporal durante o período experimental.

A eficiência da transformação da MS em ganho de peso foi avaliada por meio da conversão alimentar (CA), ao passo que a da energia, por meio da eficiência energética (CE), não sendo verificadas diferenças $(\mathrm{P}=0,05)$ entre os híbridos de milho testados, observando-se valor médio entre tratamentos de $5,04 \mathrm{~kg}$ MS/kg de ganho de peso e 13,64 Mcal ED/kg ganho de peso, respectivamente. Costa (2001), avaliando diferentes pesos de abate de novilhos superprecoces Red Angus, utilizou silagem de milho como volumoso, na relação 56,2:43,8, e encontrou como média, para os diferentes pesos de abate, CA de 5,51 e CE de 15,05, sendo que, nos animais abatidos com $340 \mathrm{~kg}$, foi verificada a melhor eficiência, com CA de 5,09 e eficiência energética de 13,94, muito similar aos resultados deste trabalho. Comprova-se, desta maneira, a alta qualidade dos materiais genéticos avaliados para a produção de silagem, que pode ser incluída em dietas destinadas à terminação de animais superprecoces, uma vez que, após o período final de avaliação em confinamento, os animais encontravam-se com peso médio final de $357,0 \mathrm{~kg}$, em uma situação muito próxima à condição de abate.

Na análise dos períodos de confinamento, obser- vou-se comportamento linear para o CMSD e CEDD, conforme ilustra a Figura 1, havendo incremento de 25,8 g e 76,1 calorias, a cada dia, com o avanço do período dos animais em confinamento. Estes resultados corroboram as observações feitas por Valadares Filho et al. (1997), sobre o comportamento de ingestão de alimentos dos ruminantes, durante seu desenvolvimento corporal, em que o CMSD aumenta com o desenvolvimento corporal dos animais, sendo mais bem expresso em relação ao peso do animal. O CMSP $=0,017853+0,000154 \mathrm{X}-0,0000015 \mathrm{X}^{2}$; $\mathrm{CMSM}=0,069568+0,000728 \mathrm{X}-0,0000062 \mathrm{X}^{2} ;$ $\mathrm{CEDP}=0,044531+0,000541 \mathrm{X}-0,000005 \mathrm{X}^{2}$; e $\mathrm{CEDM}=0,173044+0,00247-0,0000206 \mathrm{X}^{2}$ apresentaram comportamento quadrático, conforme a evolução do período de confinamento ( $\mathrm{X}=$ dias), atingindo os maiores valores durante o segundo período, com 2,21\%; 90,81g/kg,75; 5,98 Mcal/100 kg PV e 246 $\mathrm{Mcal} / \mathrm{kg}^{0,75}$, respectivamente (Tabela 7).

Analisando os períodos de confinamento (Tabela 7), para o CFDN e CFDA, expressos nas diferentes formas, houve diferenças $(\mathrm{P}<0,05)$ entre os períodos. As equações de regressão que melhor representaram o $\mathrm{CFDND}=2,36648+0,10333 \mathrm{X}$ e CFDAD $=1,089574$ $+0,005555 \mathrm{X}$ apresentaram comportamento linear e crescente, ao passo que, quando expressos por meio do CFDNP $=0,009+0,000042 \mathrm{X}-0,00000047 \mathrm{X}^{2}$; CFDNM $=0,035179+0,000219 \mathrm{X}-0,00000196 \mathrm{X}^{2}$; CFDAP $=0,003947+0,0000318 \mathrm{X}-0,00000031 \mathrm{X}^{2} \mathrm{e}$ CFDAM $=0,015388+0,000153 \mathrm{X}-0,0000013 \mathrm{X}^{2}$, apresentaram comportamento quadrático.

Para o GMD, observou-se comportamento quadrático, conforme ilustra a Figura 2, apresentando o ponto de máxima aos 59 dias, com ganho de 1,481 kg/dia. O GMD foi menor no primeiro período, pois os animais ainda estavam em fase de adaptação (dieta e manejo), apesar do período de adaptação utilizado - dez dias. A redução numérica no GMD (16,3\%), a partir do 59으 dia, pode ser explicada principalmente pela maior energia gasta para manutenção e para ganho de peso, pela maior demanda de energia em função da composição do ganho de peso, como pode ser observado nas equações de predição das necessidades energéticas do NRC (1996) e ARC (1980). Para o GEC, verificou-se aumento linear frente aos períodos de confinamento, revelando maior deposição de gordura subcutânea no terceiro e quarto períodos de confinamento.

Na análise dos períodos de confinamento, observou-se comportamento quadrático para CA (Figura 3) e CE,

\section{R. Bras. Zootec., v.33, n.4, p.1016-1028, 2004}


convergindo os pontos de mínima aos 53 dias, apresentando a melhor eficiência, com CA de 4,484 e CE de 12,165 Mcal/kg ganho de peso. A resposta obtida encontra-se associada à relação entre a quantidade de matéria seca consumida e taxa de ganho de peso. As médias dos parâmetros CA e CE, referentes aos períodos de avaliação em confinamento, são apresentadas na Tabela 7.

Tabela 7 - Ganho de peso médio diário (GMD) e ganho em estado corporal (GEC), conversão alimentar (CA), eficiência energética (CE), consumo médio diário de matéria seca (CMS), fibra em detergente neutro (CFDN), fibra em detergente ácido (CFDA) e energia digestível (CED), expresso por $\mathrm{kg} /$ animal/dia e Mcal/animal/dia (CMSD, CFDND, CFDAD e CEDD), por $100 \mathrm{~kg}$ de peso vivo (CMSP, CFDNP, CFDAP e CEDP) e por unidade de peso metabólico (CMSM, CFDNM, CFDAM e CEDM), de acordo com o período de confinamento

Table 7 - Average daily weight gain ( $A D G$ ), body condition gain (BCG), feed conversion ( $F C$ ), energy efficiency (EE), average daily dry matter intake (DMI), neutral detergent fiber intake (NDFI), acid detergent fiber intake (ADFI), and digestible energy intake (DEI), per kg/animal/day or Mcal/animal/day (DMID, NDFID, ADFID and DEID), per $100 \mathrm{~kg}$ of live weight (DMIP, NDFIP, ADFIP and DEIP) per unit of metabolic weight (DMIM, NDFIM, ADFIM and DEIM), according to the confinement period

\begin{tabular}{|c|c|c|c|c|c|c|}
\hline \multirow[t]{2}{*}{$\begin{array}{l}\text { Parâmetros } \\
\text { Parameters }\end{array}$} & \multicolumn{4}{|c|}{$\begin{array}{l}\text { Períodos } \\
\text { Periods }\end{array}$} & \multirow[t]{2}{*}{$\mathrm{NS}^{1}$} & \multirow[t]{2}{*}{ CV (\%) } \\
\hline & 1 & 2 & 3 & 4 & & \\
\hline $\begin{array}{l}\text { GMD } \\
A D G\end{array}$ & 0,919 c & 1,367ab & $1,476 \mathrm{a}$ & $1,239 \mathrm{~b}$ & 0,0001 & 11,04 \\
\hline $\begin{array}{l}\text { GEC } \\
B C G\end{array}$ & 0,12 c & 0,13 bc & $0,20 \mathrm{ab}$ & 0,25 a & 0,0001 & 17,80 \\
\hline $\begin{array}{l}\text { CA } \\
F C\end{array}$ & 5,843 a & $4,657 \mathrm{~b}$ & $4,596 \mathrm{~b}$ & 5,682 a & 0,0001 & 10,96 \\
\hline $\begin{array}{l}\text { CMSD } \\
D M I D\end{array}$ & $5,309 \mathrm{~d}$ & 6,313 c & $6,680 \mathrm{~b}$ & 6,992 a & 0,0001 & 2,72 \\
\hline $\begin{array}{l}\text { CMSP } \\
D M I P\end{array}$ & $2,03 \mathrm{c}$ & $2,21 \mathrm{a}$ & $2,12 \mathrm{~b}$ & $2,03 \mathrm{c}$ & 0,0001 & 1,84 \\
\hline $\begin{array}{l}\text { CMSM } \\
\text { DMIM }\end{array}$ & $81,58 \mathrm{c}$ & $90,81 \mathrm{a}$ & $89,20 \mathrm{ab}$ & $87,48 b$ & 0,0001 & 2,00 \\
\hline $\begin{array}{l}\text { CEDD } \\
\text { DEID }\end{array}$ & $13,927 d$ & $17,082 \mathrm{c}$ & $18,080 \mathrm{~b}$ & $18,921 \mathrm{a}$ & 0,0001 & 2,68 \\
\hline $\begin{array}{l}\text { CEDP } \\
\text { DEIP }\end{array}$ & $5,32 \mathrm{~d}$ & 5,98 a & $5,73 \mathrm{~b}$ & $5,50 \mathrm{c}$ & 0,0001 & 1,84 \\
\hline $\begin{array}{l}\text { CEDM } \\
\text { DEIM }\end{array}$ & $0,214 \mathrm{c}$ & $0,246 \mathrm{a}$ & $0,241 \mathrm{ab}$ & $0,237 \mathrm{~b}$ & 0,0001 & 1,98 \\
\hline $\begin{array}{l}C E \\
E E\end{array}$ & 15,338 a & $12,609 b$ & $12,431 b$ & $15,384 \mathrm{a}$ & 0,0001 & 10,94 \\
\hline $\begin{array}{l}\text { CFDAD } \\
\text { ADFID }\end{array}$ & $1,164 \mathrm{~d}$ & $1,377 \mathrm{c}$ & $1,457 \mathrm{~b}$ & $1,526 \mathrm{a}$ & 0,0001 & 2,92 \\
\hline $\begin{array}{l}\text { CFDAP } \\
\text { ADFIP }\end{array}$ & $0,44 \mathrm{c}$ & 0,48 a & $0,46 \mathrm{~b}$ & $0,44 \mathrm{c}$ & 0,0001 & 1,85 \\
\hline $\begin{array}{l}\text { CFDAM } \\
\text { ADFIM }\end{array}$ & 17,89 c & 19,81 a & $19,45 \mathrm{ab}$ & 19,09b & 0,0001 & 2,04 \\
\hline $\begin{array}{l}\text { CFDND } \\
\text { NDFID }\end{array}$ & $2,521 \mathrm{~d}$ & $2,879 \mathrm{c}$ & $3,047 \mathrm{~b}$ & 3,189 a & 0,0001 & 2,59 \\
\hline $\begin{array}{l}\text { CFDNP } \\
\text { NDFIP }\end{array}$ & $0,96 \mathrm{~b}$ & $1,01 \mathrm{a}$ & $0,97 \mathrm{~b}$ & 0,93 c & 0,0001 & 1,83 \\
\hline $\begin{array}{l}\text { CFDNM } \\
\text { NDFIM } \\
\end{array}$ & $38,75 \mathrm{c}$ & $41,42 \mathrm{a}$ & $40,69 a b$ & 39,89b & 0,0001 & 1,95 \\
\hline
\end{tabular}

\footnotetext{
R. Bras. Zootec., v.33, n.4, p.1016-1028, 2004
} 
CMS $(D M I)=4,968944+0,025802 X \quad \operatorname{CED}(D E I)=13,00799+0,076085 X$ $\mathrm{P}<0,0001 ; \mathrm{R}^{2}=0,6490$

$P<0,0001 ; R^{2}=0,6670$

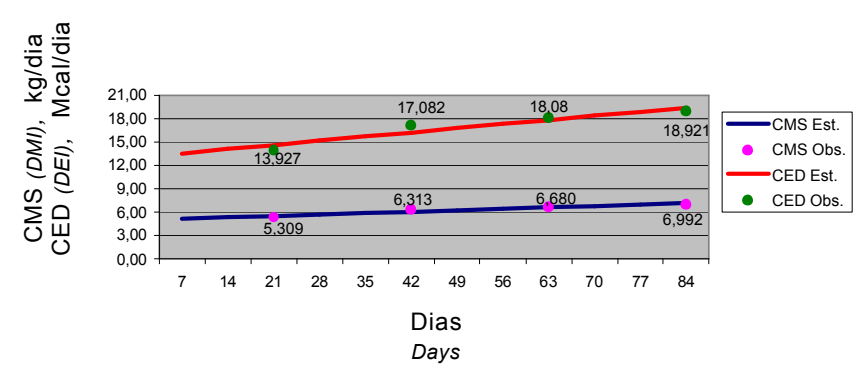

Figura 1 - Estimativa do consumo diário de matéria seca (CMS) e consumo diário de energia digestível (CED) dos animais em confinamento.

Figure 1 - Estimate of daily dry matter intake (DMI) and daily digestible energy intake (DEI) of confined males.

GMD ADG $=0,127249+0,045838 X-0,000388 X^{2}$ $\mathrm{P}<0,0001 \quad \mathrm{R}^{2}=0,6911$

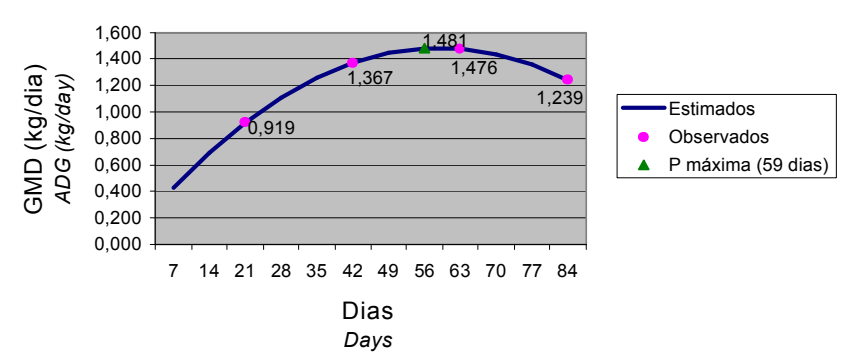

Figura 2 - Estimativa do ganho médio diário (GMD) dos animais em confinamento.

Figure 2 - Estimate of average daily weight gain (ADG) of confined males.
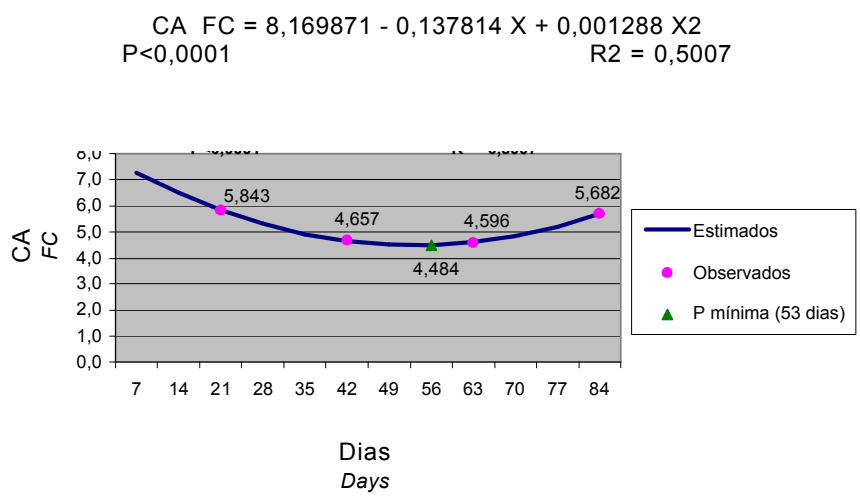

Figura 3 - Estimativa da conversão alimentar (CA) dos animais em confinamento.

Figure 3 - Estimate of feed conversion (FC) of confined males.

\section{Conclusões}

As silagens dos híbridos de milho Agroceres AG-5011, Braskalb XL-344 e Cargill C-806, avaliadas por meio de bezerros confinados, em fase de crescimento, apresentam semelhanças quanto ao ganho de peso médio diário, ganho em escore corporal, conversão alimentar, eficiência energética e consumo médio diário de matéria seca expresso em $\mathrm{kg} /$ animal. Entretanto, quando o consumo médio diário de matéria seca foi expresso em função do peso vivo e tamanho metabólico, animais alimentados com silagem do híbrido de milho Agroceres AG-5011 apresentaram maior consumo.

Animais alimentados com silagem do híbrido de milho Agroceres AG-5011 apresentam maior consumo médio diário de fibra em detergente ácido, em relação aos que receberam as silagens dos híbridos Braskalb XL-344 e Cargill C-806, que, por sua vez, são semelhantes entre si.

Os híbridos avaliados são indicados como materiais genéticos de alta qualidade para produção de silagem, promovendo ganho de peso superior a $1,2 \mathrm{~kg}$, quando utilizados em dietas com relação volumoso concentrado de 70:30.

\section{Literatura Citada}

AGRICULTURAL RESEARCH COUNCIL - ARC. The nutrients requirements of ruminants livestock. Technical review by on Agricultural Research Council Working Patry, London, 1980. 351p.

ANDRIGUETTO, J.M.; PERLY, L.; MINARDI, I. et al. Nutrição animal. v.1. São Paulo: Nobel, 1981. 395p.

ASSOCIATION OF OFFICIAL ANALYTICAL CHEMIST AOAC. Official methods of analysis. 14.ed. Washington, D.C.: $1984.141 \mathrm{p}$.

ASSOCIATION OF OFFICIAL ANALYTICAL CHEMIST AOAC. Official methods of analysis. 16.ed. Washington, D.C.: 1995. 1094p.

BAIL, C.A.T.; BRONDANI, I.L.; RESTLE, J. Níveis de concentrado na fase de terminação em confinamento para novilhos previamente mantidos em pastagem nativa ou cultivada. Ciência Rural, v.30, n.1, p.151-157, 2000.

BORGES, A.L.C.C.; GONÇALVES, L.C.; RODRIQUEZ, N.M. et al. Qualidade de silagens de híbridos de sorgo de porte alto, com diferentes teores de tanino e umidade no colmo. Pesquisa Brasileira Medicina Veterinária e Zootecnia, v.49, n.4, p.441-452, 1997.

BRONDANI, I.L.; ALVES FILHO, D.C. Produção de silagem de qualidade. In: RESTLE, J.; BRONDANI, I.L.; ALVES FILHO, D.C. et al. (Eds.) Produção intensiva com qualidade em bovinos de corte. Santa Maria: Universidade Federal de Santa Maria, 1998. p.82-88.

COSTA, E.C. Desempenho em confinamento e características da carcaça e da carne de novilhos Red Angus superprecoces abatidos com diferentes pesos. Santa Maria: 
Universidade Federal de Santa Maria, 2001 99p. Dissertação (Mestrado em Zootecnia) - Universidade Federal de Santa Maria, 2001.

DNPEA-BRASIL. Ministério da Agricultura. Departamento Regional de Pesquisa Agropecuária: Divisão de Pesquisas Pedológicas. (Boletim Técnico, 30) Levantamento de reconhecimento de solos do Rio Grande do Sul. Rio de Janeiro, 1973. 431p.

EIFERT, E.C. Silagens de sorgo e de triticale associados a níveis de concentrado para alimentação de terneiros de corte desmamados precocemente. Santa Maria: Universidade Federal de Santa Maria, 2000. 150p. Dissertação (Mestrado em Zootecnia) - Universidade Federal de Santa Maria, 2000.

ELIZALDE, H.F. El valor nutritivo de los ensilages. Revista Argentina Produção Animal, v.15, n.1, p.103-121. 1995.

FANCELLI, A.L.; DOURADO-NETO, D. Produção de milho. Guaíba-RS: Agropecuária. 2000. 360 p.

FLORES, J.L.C. Desempenho em confinamento e características de carcaça e da carne de bovino de diferentes grupos genéticos abatidos aos quatorze meses. Santa Maria: Universidade Federal de Santa Maria, 1997, 109p. Dissertação (Mestrado de Zootecnia) - Universidade Federal de Santa Maria, 1997.

GOERING, H.K.; Van SOEST, P.J. Forage fiber analysis: apparatus reagents, procedures and some applications. Washington, D.C.: 1970. (Agricultural Handbook, 379). 379p.

LATIN AMERICAN TABLES OF FEED COMPOSITION. Flórida: University of Florida, 1974. p.11-16.

McDOnAlD, P.; HENDERSON, N.; HERON, S. The biochemistry of silage. 2.ed. New York: Chalcombe Publications, 1991. 339p.

MERTENS, D.R. Análise da fibra e sua utilização na avaliação de alimentos e formulação de rações. In: SIMPÓSIO INTERNACIONAL DE RUMINANTES. REUNIÃO ANUAL DA SOCIEDADE BRASILEIRA DE ZOOTECNIA, 29., 1992, Lavras. Anais... Lavras: Sociedade Brasileira de Zootecnia, 1992. p.188-219.

MORENO, J.A. Clima do Rio Grande do Sul. Porto Alegre: Secretaria da Agricultura. 1961. 41p.

MÜLBACH, P.R.F. Silagem: produção com controle de perdas. In: LOBATO, J.F.P., BARCELLOS, J.O.J.; KESSLER, A.M. et al. (Eds.) Produção de bovinos de corte. Porto Alegre: EDIPUCRS, 1999. p.97-120.

NATIONAL RESEARCH COUNCIL - NRC. Nutrient requirements of domestic animals. 7.rev.ed. Washington: National Academy Press. 1996. 242p.

NUSSIO, L.G. Silagem de milho. In: PEIXOTO, A.M.; MOURA, J.C.; NUSSIO, L.G. et al. (Eds.) Alimentação suplementar. Piracicaba: Fundação de Estudos Agrários Luiz de Queiroz, 1999. p.27-46.
PILAR, R.C.; RESTLE, J.; SANTOS, G.L. et al. Silagens de milho (Zea mays, L.) ou capim-elefante (Pennisetum purpureum, Schum.) cv. Napier para alimentação de terneiros de corte confinados. Ciência Rural, v.24, n.2, p.387-392, 1994.

PIMENTEL, J.J.O.; SILVA, J.F.C.; FILHO, S.C.V. et al. Efeito da suplementação protéica no valor nutritivo de silagens de milho e sorgo. Revista Brasileira de Zootecnia, v.27, n.5, p.1042-1049, 1998.

RESTLE, J. Comportamento reprodutivo do rebanho de gado de corte da fazenda experimental de criação experimental agronômica da UFRGS. Porto Alegre: Universidade Federal do Rio Grande do Sul, 1972. (Seminário da disciplina de Técnicas de Pesquisa). Curso de Universidade Federal do Rio Grande do Sul, 1972.

RESTLE, J.; EIFERT, E.C.; BRONDANI, I.L. et al. Produção de terneiros para abate aos 12 meses, alimentados com silagens de milho colhidos a duas alturas de corte, associadas a dois níveis de concentrado. In: REUNIÃO ANUAL DA SOCIEDADE BRASILEIRA DE ZOOTECNIA, 36., 1999, Porto Alegre. Anais... Porto Alegre: Sociedade Brasileira de Zootecnia, 1999a. p.301.

RESTLE, J.; NEUMANN, M.; COSTA, E.C. Silagens de diferentes híbridos de milho (Zea mays, L.) avaliados através do desempenho de bezerros confinados. Ciência Rural. (No prelo). 2004.

RESTLE, J.; NUCCI, E.P.D.; FLORES, J.L.C. Palha de trevo vesiculoso (Trifolium vesiculosum Savi cv. Yuchi) como substituto da silagem de milho na alimentação de novilhos confinados. Ciência Rural, v.30, n.2, p.325-331, 2000.

STATISTICAL ANALYSES SYSTEM - SAS. SAS/STAT user's guide: statistics 7 ed. Version 6.11 v. 2. Cary: 1997. 943p.

TILLEY, J.M.; TERRY R.A. A two-stage technique for the in vitro digestion of forage crops. Journal British Grassland Society, v.18, p.104-111, 1963.

VALADARES FILHO, R.F.D.; GONÇALVES, L.C. RODRIGUEZ, N.M. et al. Níveis de proteína em dieta de bovinos. 1. Consumo e digestibilidade aparentes totais e parciais. Revista Brasileira Zootecnia, v.26, n.6, p.1252-1258, 1997.

Van SOEST, P.J. Nutritional ecology of the ruminant. 2.ed. Ithaca New York: Cornell University Press, 1994. 476p.

WALDO, D.R. Symposium: forage utilization by the lactating cow. Effect of forage quality on intake and forage concentrate interactions. Journal of Dairy Science, n.69, p.617-631, 1986.

Recebido em: 22/07/02 Aceito em: 02/10/03 